\section{Reply from Mrs Bottomley}

\section{Dear Fiona}

Thank you for your letter of 27 April in which you raise a number of concerns over the introduction of supervision registers for severely mentally ill people.

It may be helpful if I reiterate the background to the registers. The Government, the College, most observers and the majority of the general public support the principle of local comprehensive care for mentally ill people in an environment which is the least restrictive and is as handy as is compatible with the health and safety of the patient and the protection of the public. If this consensus is to be maintained, particularly in the face of recent tragic incidents involving severely mentally ill people, it is essential that mechanisms are in place which effectively identify those patients who are at most risk of harming themselves or others. It is these patients who should then be given the highest priority for care and treatment. We believe that the supervision registers, where operated as an integral part of the Care Programme Approach, offer the means to do this, thereby protecting both this vulnerable group, and the wider public.

To turn to your detailed points, we disagree that the criteria for inclusion on the register are too broad. The guidelines state that only those patients who are considered to be at significant risk of either suicide, serious violence to others, or severe self-neglect should be included on registers. We cannot agree that "this is likely to involve a considerable proportion of patients undergoing psychiatric care". We have deliberately tried to make the criteria flexible, without unduly impinging upon the judgement of individual clinicians.

With regard to your second point, we cannot acccept that the registers would cost $£ 77$ million to implement, according to the guidelines. The registers are an integral part of the Care Programme Approach, and require no new services to be delivered. Where the Care Programme Approach is being implemented, the introduction of supervision registers should add little to the care planning process. Again, it must be stressed, that the registers are designed for the most severely mentally ill patients, to whom the highest priority should be given. If community care is to work for severely mentally ill people, it is essential that resources are targeted effectively. We believe that registers provide the mechanism to achieve that.

We appreciate your concerns over the position of clintcians who may be accused of negligence if a patient who has not been placed on a register commits serious violence or suicide. I would stress that the introduction of supervision registers does not add to (or subtract from) the existing legal and ethical responsibilities placed on clinicians. In such a case clinicians may well be called upon to justify their decisions in any event, registers or not; the care planning process, including the decision whether or not to include a patient on a register, offers the mental health team an opportunity to demonstrate that such decisions were taken after due consideration of all relevant factors. Similarly, we cannot see that the existence of supervision registers fundamentally alters the reality of making risk assessments on a daily basis. The introduction of registers should make such risk assessment a more systematic process.

You claim that the arrangements for withdrawal from the register are unclear. We would disagree. When a patient no longer satisfies the criteria for inclusion, he or she should be removed from the register. Granted that some patients are unlikely to be removed from the register, this merely reflects the fact that they are patients most at risk.

We note your concern that the introduction of supervision registers will act as a disincentive to members of the team becoming key workers for patients on the register. We are happy to offer the reassurance that the registers impose no new legal or ethical duties upon staff. We appreciate the worries that staff have about personal safety and I would argue that registers will be of assistance in ensuring that staff are better informed about the nature of any risk.

You argue that the inclusion of patients with personality disorders amongst the criteria will divert resources from the seriously mentally ill. I must stress again that registers are a mechanism for identifying those patients most at risk. If patients with personality disorders come within this category, they should be included on registers.

You raise a series of points about the civil liberties aspects of registers, the danger that registers will become merely a list, and the possible strains that registration may cause to the therapeutic relationship. We agree that it is vital that the issue of registration is treated with the utmost sensitivity, that confidentiality is respected, and that inclusion on a register does not become a mere paper exercise. In the longer term, if supervision registers are to be acceptable to patients and staff, they must demonstrate clear benefits. If they are used, as we intend, to facilitate the effective prioritisation of care, ensuring that the most vulnerable patients are protected, then we believe both patients and stafi will benefit.

You are concerned that patients' GPs will know about their inclusion on the register, which may make it difficult for them to receive general 
medical services. We believe it is only right that the patient's GP should have access to this information. I would remind you of the criticisms contained within the report of the Inquiry into the care and treatment of Christopher Clunis of the repeated failures of different agencies to pass on information concerning Mr Clunis's incidents of violence. The recent guidance on the new arrangements for the removal of violent patients from GP lists specifically notes that the new powers are not for use in the case of psychiatric patients.

We appreciate the concerns of your members that the process of registering patients and allowing for appeals will cut into time for patient care. However, we believe that where the Care Programme Approach is being implemented, the introduction of registers will not create unmanageable amounts of extra bureaucracy.

\section{Update following the meeting of the Executive and Finance Committee, 4 June 1994}

I should like to report to Members and Fellows of the College the recent developments relating to the introduction of the Supervision Register.

This matters was raised again at the meeting of the College's Executive and Finance Committee on 4 June, at which the Secretary of State for Health's response to my letter of 27 April 1994 was received.

Following my correspondence with the Secretary of State for Health, I have now had an invitation from Dr Rachel Jenkins, Senior Principal Medical Officer at the Department of Health, to meet to discuss the matter. We have agreed
Finally, you draw attention to the recommendations of the report of the Inquiry into the care and treatment of Christopher Clunis, in particular, those proposals for establishing special supervision groups, with new funding. We find this surprising, given the objections you have outlined against supervision registers. The idea of a new national register would raise very considerable anxieties over civil liberties, and offer a far greater risk to the therapeutic relationship than local registers.

We are anxious that psychiatrists work to make supervision registers a successful method of prioritising patients who are at special risk so that their needs are met and they receive the most appropriate care and treatment.

I hope this is helpful.

VIRGINIA BOTTOMLEY

that the College will collaborate with the Department of Health in developing guidelines concerning the implementation of the Register.

I should like to assure Members and Fellows that in view of the level of concern regarding the proposals, the College will in due course be issuing advice to the membership of the College, although it is not clear at this stage whether this will be produced in conjunction with the Department of Health.

I should be interested to hear from any Members or Fellows who can report instances where a Supervision Register is being implemented successfully.

Dr F. CaldicotT, President, Royal College of Psychiatrists 